\title{
A Study on the Mechanical Properties of the Hybrid Fiber-Reinforced Mortar Using the Macro Steel and Micro Carbon Fibers
}

\author{
Gwang Hee Heo ${ }^{1}$, Jong Gun Park ${ }^{2,}$, Hyung Min Jun ${ }^{3}$, Dong Ju Seo ${ }^{4}$, Sung Gon Koh ${ }^{5}$ \\ ${ }^{1}$ Department of International Civil and Plant Engineering, Konyang University, Nonsan, Republic of Korea \\ ${ }^{2}$ Public Safety Research Center (PSRC), Konyang University, Nonsan, Republic of Korea \\ ${ }^{3}$ Department of Disaster and Safety Engineering, Konyang University, Nonsan, Republic of Korea \\ ${ }^{4}$ Moowang Construction, Iksan, Republic of Korea \\ ${ }^{5}$ Department of Cadastre \& Civil Engineering, Jeonju Vision College, Jeonju, Republic of Korea
}

Email address:

2630@hanmail.net (J. G. Park), park2630@konyang.ac.kr (J. G. Park)

${ }^{*}$ Corresponding author

\section{To cite this article:}

Gwang Hee Heo, Jong Gun Park, Hyung Min Jun, Dong Ju Seo, Sung Gon Koh. A Study on the Mechanical Properties of the Hybrid Fiber-Reinforced Mortar Using the Macro Steel and Micro Carbon Fibers. American Journal of Civil Engineering.

Vol. 8, No. 6, 2020, pp. 128-138. doi: 10.11648/j.ajce.20200806.11

Received: October 29, 2020; Accepted: November 12, 2020; Published: November 19, 2020

\begin{abstract}
In the present study, an experiment was conducted to investigate the mechanical properties such as fluidity, compressive strength and flexural performance (flexural strength and toughness) of a single fiber-reinforced mortar (FRM) using only macro steel fiber (SF) or micro carbon fiber (CF) with different material properties and SF-CF hybrid FRM using a mixture of macro SF and micro CF. The specimens incorporated macro SF and micro CF in the mix proportions of 100-0\%, $75-25 \%, 50-50 \%, 25-75 \%$ and $0-100 \%$ by volume at a total fiber volume fraction of $1.0 \%$. Their mechanical properties were further compared and reviewed with the plain mortar at 28 days of age. The experimental results of fresh mortar showed that the table flow of mortar using only macro SF was slightly reduced compared to plain mortar, whereas the table flow of mortar using only micro CF and SF-CF hybrid mortar decreased significantly with increase of micro CF. It was revealed from the test of the hardened mortar that the SF-CF=75-25\% (M3) specimen showed the highest compressive and flexural strength, and the $\mathrm{SF}-\mathrm{CF}=50-50 \%$ (M6) specimen obtained the highest flexural toughness. Therefore, it was possible to confirm the synergistic reinforcement effect of that enhanced the strength and improved the flexural performance by hybrid of macro SF and micro CF. Based on the results of this experiment, the optimal mix proportion of SF-CF hybrid FRM is proposed in this paper to improve the compressive strength, flexural strength and flexural toughness.
\end{abstract}

Keywords: Macro Steel Fiber, Micro Carbon Fiber, Hybrid Fiber-Reinforced Mortar, Flexural Performance, Fluidity

\section{Introduction}

Cement-based composite materials have been used worldwide as major construction materials for buildings and civil engineering structures till now due to their excellent compressive strength [1-3]. However, cement-based composite materials have two well-known disadvantages that they not only are vulnerable to flexural tensile strength, but also have brittle properties including low ductility and lack of strain capacity. This is why studies have been continuously conducted on fiber-reinforced cement composites (FRCC) in which discontinuous and short fibers are irregularly dispersed in the cement composite in order to improve the disadvantages of such brittle properties [4-6]. Currently, fibers used in FRCC include inorganic fibers such as steel fibers, glass fibers and carbon fibers etc. as well as organic fibers such as aramid fibers, polypropylene fibers, vinylon fibers, and nylon etc. [7, 8]. Fibers are divided into micro and macro fibers according to their size (length and diameter) [9]. Although only single fibers have been limitedly used for FRCC in general, various studies are being conducted on hybrid fiber-reinforced cement composites (HyFRCC) that can maximize the effects which single fibers cannot exert by mixture of two or more types of fibers having different material properties in an appropriate ratio. In case of HyFRCC with different material properties, effects which are 
not expected merely with single fiber reinforcement can be obtained. If macro and micro fibers are properly mixed and used, it is possible to effectively control cracks and improve durability within the range of low mixture content of fiber. In addition, it is also expected to improve the flexural performance by simultaneously increasing the strength and ductility [10-13].

Figure 1 shows the fiber crack control mechanism applied

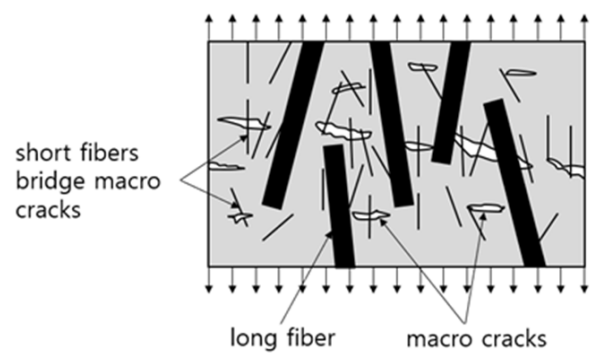

(a) First phase of loading according to the fiber size to control macro and micro cracks occurring in HyFRCC. From the results of this synergistic mechanism, it is made known that the long and strong fibers can control macro cracks and the short and soft fibers can control crack initiation and propagation of micro cracks. That is, by mixing and using two or more kinds of fibers in an appropriate ratio, it is possible to improve strength and ductility at the same time.

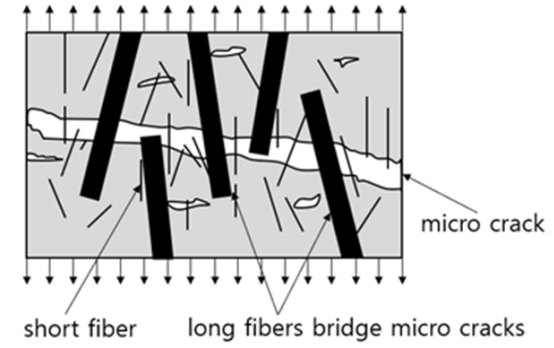

(b) Second phase of loading

Figure 1. Action of macro and micro fibers with different size.

At present, studies on high performance hybrid fiber-reinforced cement composites (HP-HyFRCC) which use a mixture of two or more other fiber types owing to development of high-strength and high-elastic reinforcing fiber materials are conducted mostly with a focus laid on developing the fiber-reinforced high toughness cement composites with high fiber volume fractions of $2.0 \%$ or more [14, 15]. However, relatively insufficient are the studies on the mechanical properties of hybrid FRM within the range of low fiber volume fraction of less than $1.0 \%$, which are widely employed in the construction industry due to economy and constructability [16].

In this study, therefore, in order to confirm the synergy reinforcement effect of the SF-CF hybrid FRM which uses a mixture of macro SF and micro $\mathrm{CF}$, it was attempted to experimentally investigate the mechanical properties such as fluidity, compressive strength and flexural performance of a single FRM and SF-CF hybrid FRM at the level of 5 experimental variables $(\mathrm{SF}-\mathrm{CF}=100-0 \%, 75-25 \%, 50-50 \%$, $25-75 \%$ and $0-100 \%$ ) divided by volume at a total fiber volume fraction of $1.0 \%$. Moreover, the flexural behavior and toughness were evaluated on the basis of the load-deflection relationship curve from the flexural performance test. The results were compared and reviewed with the plain mortar at 28 days of age.

\section{Experimental Outlines}

\subsection{Experimental Plan}

In the current study, an experiment plan was worked out to understand the mechanical behavior characteristics such as fluidity, compressive strength and flexural performance of a single FRM using only macro SF or micro $\mathrm{CF}$, and SF-CF hybrid FRM using macro SF and micro $\mathrm{CF}$ in mix. The specimens incorporated plain mortar and 5 levels of fibers in the mix proportions of $\mathrm{SF}-\mathrm{CF}=100-0 \%, 75-25 \%, 50-50 \%$, $25-75 \%$ and $0-100 \%$ by volume at a total volume fraction of $1.0 \%$. For this purpose, prepared were 3 cubic specimens with a size of $40 \times 40 \times 40 \mathrm{~mm}$ for each compressive strength test and two beam specimens with a size of $100 \times 100 \times 400$ $\mathrm{mm}$ for each flexural performance test. For experiments, it was planned to measure the table flow of fresh mortar, and to measure the compressive strength and flexural strength of hardened mortar at 28 days of age. Moreover, the flexural behavior and toughness were evaluated in the load-deflection relationship curve through the flexural performance test.

\subsection{Materials}

Used in the experiment was Ordinary Portland Cement (OPC) manufactured by S Company, with specific gravity of 3.13 and fineness of $3,860 \mathrm{~cm}^{2} / \mathrm{g}$. For fine aggregate, Jumunjin standard sand was used to make mortar homogeneous. The specific gravity of fine aggregate the surface of which is dry and saturated was 2.65. As a superplasticizer (SP), a high-performance AE water reducing agent in light yellow color which is a product of domestic D Company, being a series of polycarboxylic acid and liquid with specific gravity of 1.04 and $\mathrm{pH} 5.0 \pm 1.5$, was used to facilitate fluidity of the mortar. The macro SF used in this experiment has a diameter of $0.5 \mathrm{~mm}$, a length of $30 \mathrm{~mm}$, and a tensile strength of $1,100 \mathrm{MPa}$. The macro SF, a product of domestic K Company, is a hooked-end type with both ends hooked, and also a bundle type with several strands attached to each other to allow easy input of material. Meanwhile, the micro CF has a diameter of $0.007 \mathrm{~mm}$ and a length of $6 \mathrm{~mm}$, and the tensile strength and modulus of elasticity are 4,900 $\mathrm{MPa}$ and $230 \mathrm{GPa}$, respectively. Made from acrylic polyacrylonitrile (PAN) as raw material, it was manufactured by Japanese $\mathrm{T}$ Company. The physical properties of macro $\mathrm{SF}$ and micro CF used in this experiment are shown in Table 1 , and Figure 2 is a photograph showing the shape of fibers.

Table 1. Properties of fibers.

\begin{tabular}{lll}
\hline Characteristics & Macro SF & Micro CF \\
\hline Shape & Hooked-end & Straight \\
Length $l(\mathrm{~mm})$ & 30 & 6 \\
Diameter d $(\mathrm{mm})$ & 0.5 & 0.007 \\
Aspect ratio $(l / \mathrm{d})$ & 60 & 857 \\
Density $\left(\mathrm{kg} / \mathrm{m}^{3}\right)$ & 7850 & 1800 \\
Tensile strength $(\mathrm{MPa})$ & 1100 & 4900 \\
Elastic modulus $(\mathrm{GPa})$ & $>210$ & 230 \\
Elongation $(\%)$ & $>3.5$ & 2.1 \\
\hline
\end{tabular}




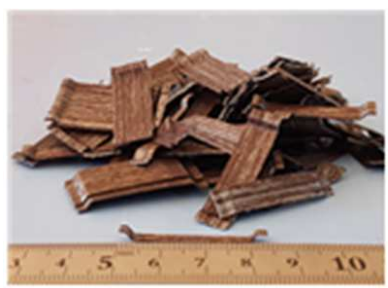

(a) Macro SF

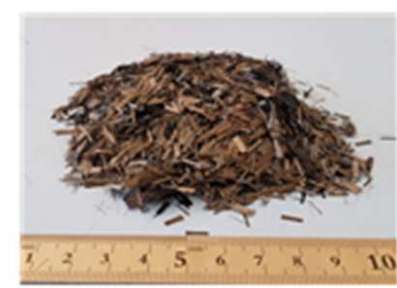

(b) Micro CF
Figure 2. Appearance of fibers used in this study.

\subsection{Mix Proportions and Specimens Preparation}

Table 2 shows the details of specimen preparation and mix proportions for plain mortar and FRM. The water to cement ratio $(\mathrm{W} / \mathrm{C})$ was set at 0.46 , and the mixing ratio (mass ratio) of the mortar was cement: standard sand: water $=1: 2: 0.46$. At this time, the coarse aggregate was not used. The amount of superplasticizer was set at $1.5 \%$ of the cement mass, and no extra superplasticizer was added to plain mortar and macro SF. For mixture of the mortar, cement and fine aggregate were first added, and mixing was carried out at low speed for 30 seconds. In an effort to secure dispersibility of fibers, they were added extra and mixed for 90 seconds in a dry mixing way. Then, water and superplasticizer were added and immediately mixed for 90 seconds. After stop for 30 seconds, the attached mortar was removed and, finally, a pan-mixer was operated again for mixture at high speed for 60 seconds. The total mixing time took about 5 minutes. All specimens were covered by plastic sheets and demolded after 24 hours casting and stored underwater for additional 27 days at the temperature of $20 \pm 2^{\circ}$ before testing.

Table 2. Specimen details and mix proportions of mortar.

\begin{tabular}{|c|c|c|c|c|c|c|c|c|c|}
\hline \multirow{2}{*}{$\begin{array}{l}\text { Specimens } \\
\text { designation }\end{array}$} & \multirow{2}{*}{ Mix type } & \multirow{2}{*}{$\begin{array}{l}\text { Total fiber volume } \\
\text { fraction }(\%)\end{array}$} & \multicolumn{2}{|c|}{ Fiber mix proportion by volume (\%) } & \multirow{2}{*}{$\mathbf{W} / \mathbf{C}$} & \multirow{2}{*}{$\begin{array}{l}\mathrm{C} / \mathrm{S} \\
\text { ratio }\end{array}$} & \multicolumn{3}{|c|}{ Unit weight $\left(\mathrm{kg} / \mathrm{m}^{3}\right)$} \\
\hline & & & Macro SF & Micro CF & & & $\mathbf{W}$ & $\mathbf{C}$ & $\mathbf{S}$ \\
\hline $\begin{array}{l}\text { M1 } \\
\text { M2 }\end{array}$ & $\begin{array}{l}\text { Single fiber } \\
\text { (steel) }\end{array}$ & & 100 & 0 & & & & & \\
\hline $\begin{array}{l}\text { M3 } \\
\text { M4 }\end{array}$ & & & 75 & 25 & & & & & \\
\hline $\begin{array}{l}\text { M5 } \\
\text { M6 }\end{array}$ & $\begin{array}{l}\text { Hybrid fiber } \\
\text { (steel }+ \text { carbon) }\end{array}$ & 1.0 & 50 & 50 & & & & & \\
\hline M7 & & & & & 0.46 & $1: 2$ & 297 & 645 & 1290 \\
\hline M8 & & & 25 & 75 & & & & & \\
\hline $\begin{array}{l}\text { M9 } \\
\text { M10 }\end{array}$ & $\begin{array}{l}\text { Single fiber } \\
\text { (carbon) }\end{array}$ & & 0 & 100 & & & & & \\
\hline $\begin{array}{l}\text { M11 } \\
\text { M12 }\end{array}$ & Plain & 0.0 & 0 & 0 & & & & & \\
\hline
\end{tabular}

Notice) W/C: Water to cement ratio, C/S: Cement to fine aggregate ratio

\subsection{Experimental Methods}

\subsubsection{Fluidity Test}

The fluidity of mortar was measured according to the "Testing method for compressive strength of hydraulic cement mortar" of KS L 5105 [17] using the table flow specified in the "Flow table for use in tests of hydraulic cement" in KS L 5111. Immediately after the mortar was discharged, it was poured into a conical mold having a lower diameter of $100 \pm 0.5 \mathrm{~mm}$, upper diameter of $70 \pm 0.5$ $\mathrm{mm}$, and height of $50 \pm 0.5 \mathrm{~mm}$, and then compacted 20 times. The table flow value of mortar is calculated as an average after drop from a height of $12.7 \mathrm{~mm}$ and the diameters were measured in different directions 4 times to gain an average.

\subsubsection{Compressive Strength Test}

In the compressive strength test, molds were manufactured according to the test method of KS L ISO 679 [18], and all strengths were measured at 28 days of age. The compressive strength was measured for the cured $40 \times 40 \times 160 \mathrm{~mm}$ cubic specimens using a $100 \mathrm{kN}$ universal testing machine (MTDI Co., Ltd., Korea, UT-100F), and a constant speed was accelerated at the loading conditions of $2400 \mathrm{~N} / \mathrm{s}$. The compressive strength was obtained from the equation (1).

$$
f_{c}=\frac{P}{b h}
$$

where, $f_{c}$ is the flexural strength (MPa), $P$ is the maximum load $(\mathrm{N}), l$ is the span $(\mathrm{mm}), b$ is the average width of the failed cross-section $(\mathrm{mm})$, and $h$ is the average height of the failed cross-section ( $\mathrm{mm})$.

\subsubsection{Flexural Performance Test}

The flexural performance test was conducted by making a beam specimen with size of $100 \times 100 \times 400 \mathrm{~mm}$ size as suggested by ASTM C 1609/C 1609 M [19] and KS F 2566 [20], and all flexural tests were performed at 28 days of age. Figure 3(a) features the shape and specifications of the specimen used in the flexural performance test and Figure 3(b) shows the test equipment set-up. For the flexural performance test, a four-point flexural loading test was applied by using a $2500 \mathrm{kN}$ universal testing machine (Instron Co., Ltd., 5597), and deflection and fracture load were measured using two linear variable displacement transducers (LVDT) installed in the center of both sides of the specimen. The deflection rate was controlled at a constant load rate of $0.2 \mathrm{~mm} / \mathrm{min}$ until the specimen was destroyed at 1/1500 of the span per minute, and the load was measured through a load cell of $850 \mathrm{kN}$ capacity. The flexural strength was calculated with the equation (2) at the maximum load.

$$
f_{r}=\frac{P l}{b h^{2}}
$$

where, $f_{r}$ is the flexural strength (MPa), $P$ is the maximum load $(\mathrm{N}), l$ is the span $(\mathrm{mm}), b$ is the average width of the failed cross-section ( $\mathrm{mm}$ ), and $h$ is the average height of the 
failed cross-section ( $\mathrm{mm})$.

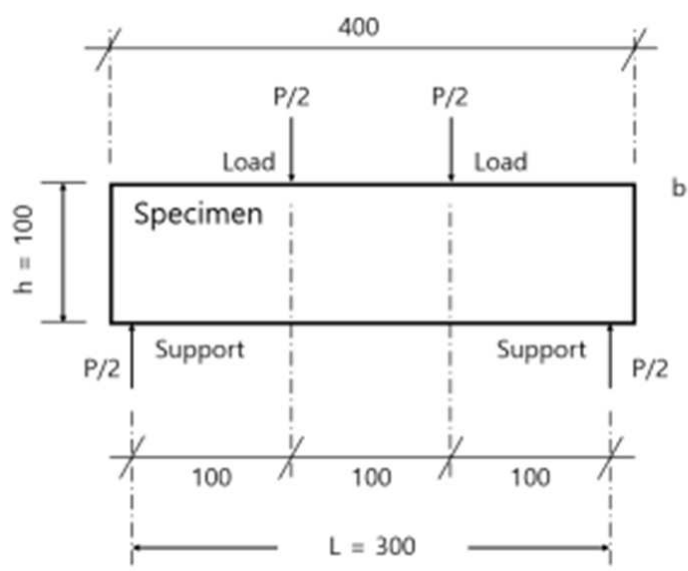

(a) Dimensions ( $\mathrm{mm}$ )

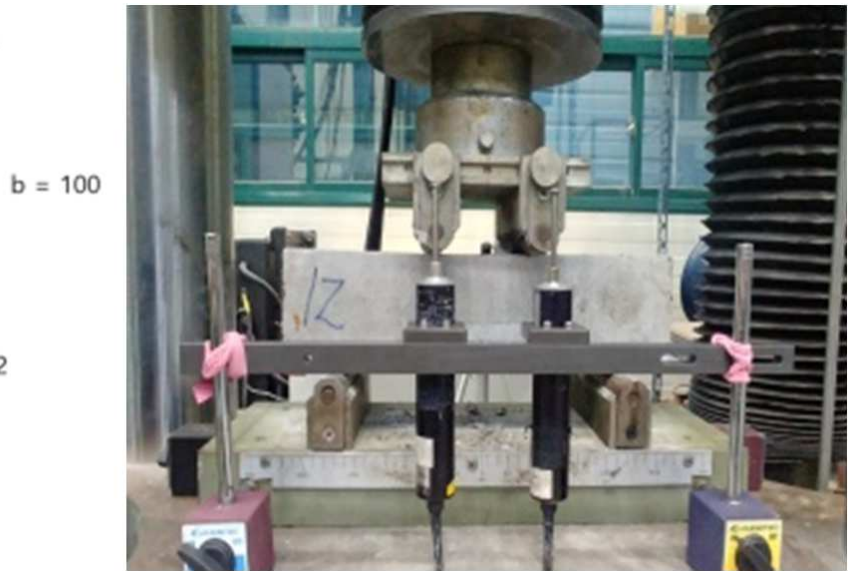

(b) Test specimen set-up

Figure 3. Test specimen set-up and dimension for four-point flexural performance.

The equivalent flexural strength is expressed as an average flexural strength at a given deflection (1/150 of the span) in the load-deflection curve obtained from the flexural performance test. It is used as an indicator to evaluate the overall flexural performance. The equivalent flexural strength was calculated from the equation (3), and Figure 4 indicates the concept of calculating the equivalent flexural strength.

$$
f_{r}^{\prime}=\frac{A_{b}}{\delta_{t b}} \times \frac{l}{b h^{2}}
$$

where, $f_{r}$ is the equivalent flexural strength (MPa), $\delta \mathrm{tb}$ is the deflection of span by $1 / 150(\mathrm{~mm}), l$ is the span $(\mathrm{mm}), b$ is the average width of the failed cross-section $(\mathrm{mm}), h$ is the average height of the failed cross-section $(\mathrm{mm})$, and $A_{b}$ (flexural toughness) represents the area $(\mathrm{kN} \cdot \mathrm{mm}, \mathrm{J})$ of the load-deflection curve up to $\delta$ t b shown in Figure 4.

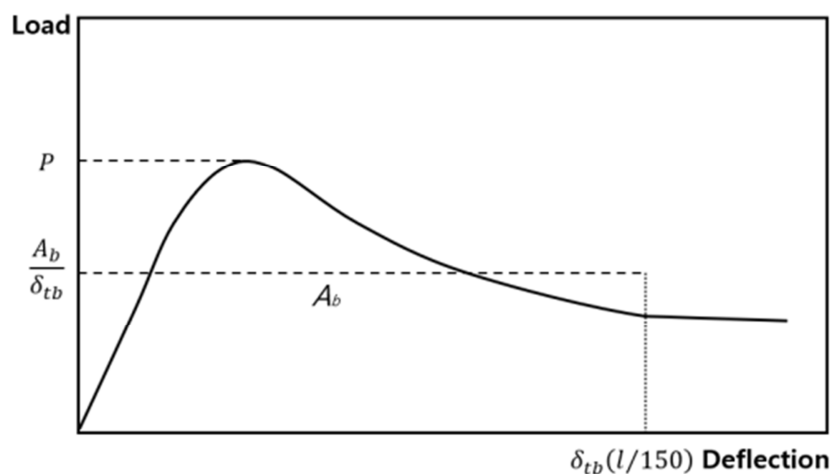

Figure 4. Calculation concept of equivalent flexural strength.

Meanwhile, the flexural toughness is calculated by accumulating the sum of the area below the load-deflection curve $(\mathrm{Ab})$ until the deflection presented in ASTM C 1609/C $1609 \mathrm{M}$ [19] and KS F 2566 [20] reaches 1/150 (2mm) of the span equation (3) in the area under the load-deflection curve obtained from the flexural performance test.

\section{Experimental Results and Discussions}

In this study, the mechanical properties such as fluidity, compressive strength, and flexural performance of a single
FRM using only macro SF or micro CF and an SF-CF hybrid FRM using a mixture of macro SF and micro $\mathrm{CF}$ at a total fiber volume fraction of $1.0 \%$ (volume ratio) were experimentally reviewed. The flexural behavior and toughness were evaluated from the load-deflection curve obtained through the flexural performance test.

\subsection{Properties of Fresh Mortar}

Figure 5 shows the table flow measurement results of the mortar mixture using only macro SF or micro CF and the SF-CF hybrid mortar mixture compared to the plain mortar. As seen in Figure 5, the table flow values of the plain mortar as well as the mortar using only macro SF were measured in the range of $206 \mathrm{~mm}$ to $210 \mathrm{~mm}$ and 192 $\mathrm{mm}$ to $197 \mathrm{~mm}$, respectively, satisfying by thus the target table flow value of $190 \mathrm{~mm}$ or more. However, the table flow value of the mortar using only micro $\mathrm{CF}$ was $110 \mathrm{~mm} \sim 112 \mathrm{~mm}$, and the micro $\mathrm{CF}$ was $25 \%, 50 \%$, and $75 \%$ in the SF-CF hybrid mortar mixture, showing a tendency of decrease from $143 \mathrm{~mm}$ upto $123 \mathrm{~mm}$ as the fiber mixture ratio increased. In the SF-CF hybrid mortar mixture, the table flow value tended to decrease in some degree as the micro CF increased, and when micro CF only was used, the value significantly decreased. It consists of tow bound together with bundles of about 12,000 untwisted continuous filaments with an average diameter of about $7 \mu \mathrm{m}$ in micro $\mathrm{CF}$, resulting in increased adhesion between the matrix and the fibers due to the high specific surface area. It was found to be almost similar to the results of the review that the fluidity was considerably lowered due to fiber aggregation [21]. On the other hand, the mixture ratio showing the lowest fluidity in the SF-CF hybrid mortar proportion was $\mathrm{SF}-\mathrm{CF}=25-75 \%$, revealing that micro $\mathrm{CF}$, unlike macro SF, was found to cause a large decrease in fluidity compared to other mortar mixtures because it has a high fiber aspect ratio and absorbs part of the mixing water. It could be confirmed, however, that the variation in fluidity of the mortar mixture using only macro SF was not very large. It is believed because macro $\mathrm{SF}$ does neither absorb the mixing water nor cause ball phenomenon of fibers. Figure 6 presents pictures featuring 
the flows of a plain mortar mixture, a mortar mixture using only macro SF or micro CF, and an SF-CF hybrid mortar mixture. As the mixture ratio of micro $\mathrm{CF}$ increases, not only the dispersibility of fibers tends to be difficult, but also the mortar mixture using only micro $\mathrm{CF}$ is not sufficiently mixed due to the ball phenomenon of fibers, adversely affecting workability because fibers are easily tangled with each other and the surface of fibers looks cracked in shape. As a result, the flow performance of the mortar mixture using only micro $C F$ is very disadvantageous in terms of flowability due to the non-hydrophilicity and ball of fibers. It is thus requested to take measures to secure dispersibility and fluidity of fibers in line with increase of the fiber mixture ratio.

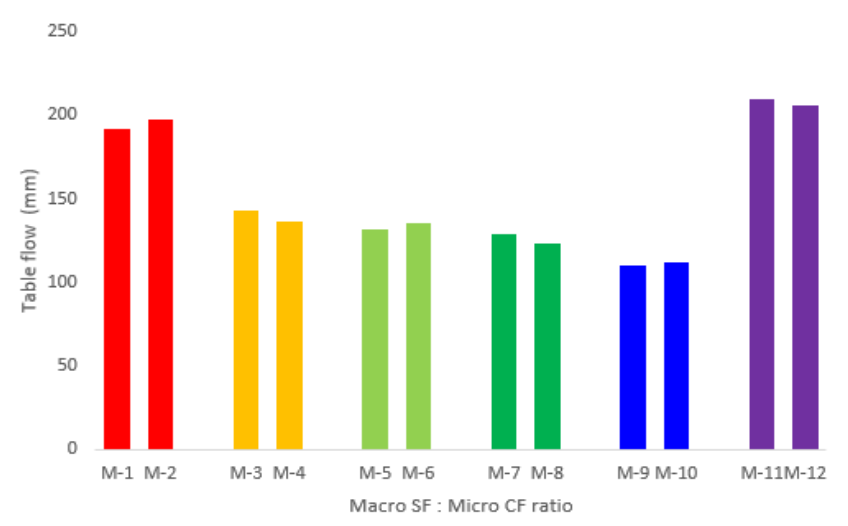

Figure 5. Variation table flow test results for each specimen.

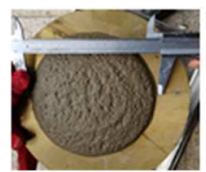

(a) Macro

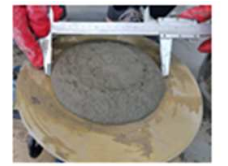

(b) SF-CF hybrid

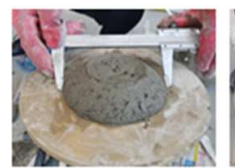

(c) Micro $\mathrm{CF}$

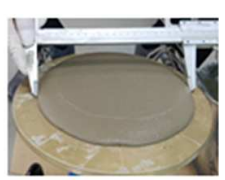

(d) Plain
Figure 6. Experimental features of flow test mortar samples.

\subsection{Properties of Hardened Mortar}

\subsubsection{Compressive Strength}

Figure 7 displays the compressive strength test results of a single FRM and SF-CF hybrid FRM compared with plain mortar. As shown in Figure 7, the average compressive strength of plain mortar was $45.7 \mathrm{MPa}$ at 28 days of age, and that of a single FRM using only macro SF and micro $\mathrm{CF}$ was measured to be $45.2 \mathrm{MPa}$ and $35.4 \mathrm{MPa}$ respectively. In case of the $\mathrm{SF}-\mathrm{CF}=75-25 \%$ (M3) specimen reinforced with hybrid, the compressive strength was appr. 47.0 $\mathrm{MPa}$, the largest one obtained in this experiment. The reason why the compressive strength increases with mixture of micro $\mathrm{CF}$ is that micro $\mathrm{CF}$ is reinforced since it is relatively small compared to macro SF. However, except for the SF-CF $=75-25 \%$ (M3) and $\mathrm{SF}-\mathrm{CF}=50-50 \%$ (M6) specimens, the compressive strength of all types of specimens was slightly lower than that of the plain mortar, and the strength was quite significantly reduced as micro $\mathrm{CF}$ increased. The average compressive strength of a single FRM using only micro CF was shown to be about $35.4 \mathrm{MPa}$ and, as a result, it was significantly reduced by about $23 \%$ compared to the plain mortar. It is judged that the strength of carbon fiber was reduced because the interfacial bonding force between the fiber and matrix in the mortar after hardening was weak due to the non-hydrophilic material on the fiber surface. These results have also been reported in previous studies [21-23] which pointed out that, due to high rate of mixed fibers, dispersibility of fibers is lowered, resulting in more and more ball of fibers and greatly affecting decrease in the compressive strength. In this experiment, the optimum mixture ratio to obtain the maximum compressive strength was found to be SF-CF=75-25\%. Consequently, the SF-CF hybrid FRM using a mixture of $\mathrm{SF}-\mathrm{CF}=75-25 \%$ is considered to be the most appropriate mixture ratio in terms of securing the compressive strength.

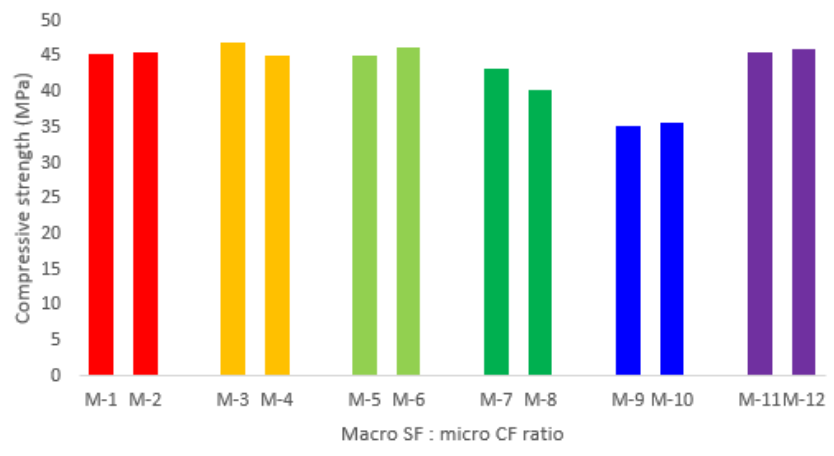

Figure 7. Variation in compressive strength test results of each specimen.

\subsubsection{Flexural Strength}

Figure 8 shows the flexural strength test results of a single FRM and SF-CF hybrid FRM in comparison with the plain mortar. As can be seen in Figure 8, the average flexural strength of the plain mortar was $3.1 \mathrm{MPa}$ at 28 days of age, and that of a single FRM using only macro SF and micro $\mathrm{CF}$ was measured to be $5.85 \mathrm{MPa}$ and $4.8 \mathrm{MPa}$, respectively. In case of the $\mathrm{SF}-\mathrm{CF}=75-25 \%$ (M3) specimen reinforced with hybrid, the flexural strength was the highest at $8.16 \mathrm{MPa}$, and it showed an improved high flexural strength of about $263 \%$ compared to plain mortar. Moreover, the average flexural strength of SF-CF hybrid FRM reinforced with SF-CF $=75-25 \%$ and $\mathrm{SF}-\mathrm{CF}=50-50 \%$ increased by about $30 \%$ and $24 \%$, respectively, compared to the average flexural strength of a single FRM using only macro SF, whereas the average flexural strength of SF-CF hybrid FRM using a mixture of $\mathrm{SF}-\mathrm{CF}=25-75 \%$ was measured to be $5.82 \mathrm{MPa}$ which is almost similar. However, the flexural strength of a single FRM using only micro CF was somewhat reduced. This indicates a higher flexural strength as the micro CF bears the stress when the initial crack occurs. As was also reported in previous studies [22-23], such result is considered to be related to the fact that mixed fibers prevented propagation of cracks by bridging effect and the flexural strength was improved by redistribution of stress. Therefore, the synergy effect of fiber reinforcement can be obtained by increasing the flexural strength if fiber is mixed in an appropriate ratio even if the mixture ratio of the fiber is small through combination of macro SF of large length and diameter and micro CF of small length and diameter. In particular, it is judged that the micro-CF is effective in controlling micro-cracks before the maximum load. In this experiment, 
the optimum mixture ratio to obtain the maximum flexural strength was found to be $\mathrm{SF}-\mathrm{CF}=75-25 \%$. Consequently, the SF-CF hybrid FRM using a mixture of SF-CF $=75-25 \%$ is considered to be the most appropriate mixture ratio in terms of securing the flexural strength.

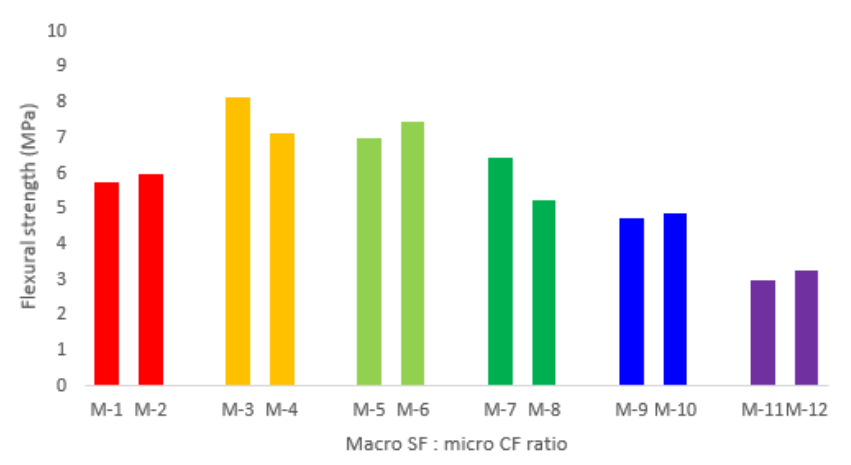

Figure 8. Variation in flexural strength test results of each specimen.

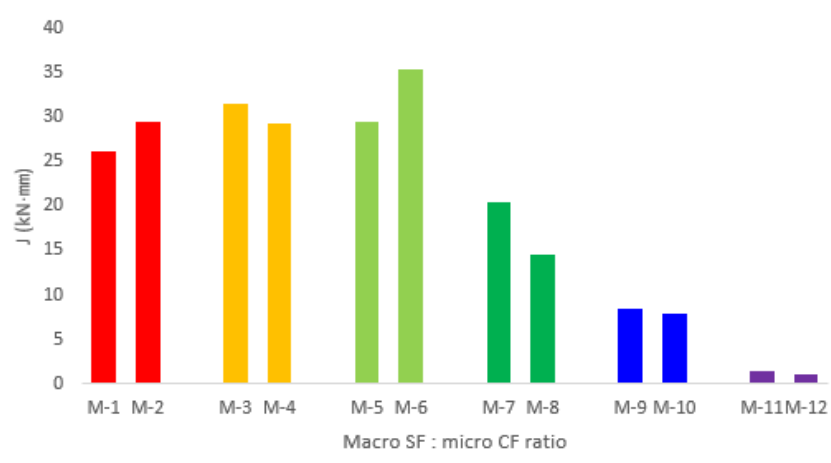

Figure 9. Variation in toughness test results of each specimen.

\subsubsection{Flexural Toughness}

Figure 9 shows the flexural toughness of a single FRM and an SF-CF hybrid FRM from a four-point flexural loading test compared with plain mortar. As seen in Figure 9, the average flexural toughness of plain mortar at 28 days of age was 1.25 $\mathrm{kN} \cdot \mathrm{mm}$, and that of a single FRM using only micro CF and macro SF was $8.16 \mathrm{kN} \cdot \mathrm{mm}$ and $27.9 \mathrm{kN} \cdot \mathrm{mm}$, respectively. Compared to plain mortar, all FRM with micro CF and macro SF showed significantly higher flexural toughness. In case of the $\mathrm{SF}-\mathrm{CF}=50-50 \%$ (M6) specimen reinforced with hybrid, the flexural toughness was the highest with $35.7 \mathrm{kN} \cdot \mathrm{mm}$, and about 28.5 times, 4.4 times and 1.3 times higher than FRM using only plain mortar, micro CF and macro SF, respectively. This is considered to be the result of reinforcing synergies between macro SF and micro $\mathrm{CF}$, as well as large crack control due to incorporation of macro SF with high rigidity, which greatly improved the flexural toughness. As a consequence, in case of the hybrid-reinforced SF-CF $=75-25 \%$ (M3) specimen, the maximum flexural strength was the highest, but the flexural toughness was slightly low due to decrease in the load-supporting capacity after cracking. In case of the SF-CF $=50-50 \%$ (M6) specimen reinforced with hybrid, however, the maximum flexural strength was slightly low, but the flexural toughness was greatly improved after cracking, indicating its highest load-supporting capacity. Since this could indicate that the less the mixed amount of micro $\mathrm{CF}$ is and the more the mixed amount of macro SF is, the greater the flexural toughness gets, it is judged that macro
SF has a greater effect on improving of the flexural toughness than micro CF has. From the experiment, it was learned that the optimal mixture ratio for obtaining the maximum flexural toughness is $\mathrm{SF}-\mathrm{CF}=50-50 \%$. It is thus reasoned that the SF-CF hybrid FRM in which SF-CF=50-50\% is mixed might be the most appropriate mixing ratio in terms of securing the flexural toughness. The hybrid FRM with such high strain capacity is considered to be more efficient if they are properly reinforced for use of the structures required to endure dynamic loads such as earthquake, impact, explosion, wind etc.

\subsubsection{Equivalent Flexural Strength and Equivalent Flexural Strength Ratio}

Table 3 summarizes the maximum flexural strength, equivalent flexural strength, and equivalent flexural strength ratio of each specimen by a four-point flexural loading test. The equivalent flexural strength was calculated on the basis of the equations presented in ASTM C 1609/C $1609 \mathrm{M}$ [19] and KS F 2566 [20]. Figure 10 shows the results of calculating the equivalent flexural strength of each specimen in a graph. As seen in Table 3, it was found that the plain mortar specimen and the single FRM specimen using only micro CF were fractured before they reached the given deflection (1/150 of the span) due to its brittle behavior, whereas the single FRM specimen using only macro SF and the SF-CF hybrid FRM specimen were destructed at further than a given deflection $(1 / 150$ of the span) due to its ductile behavior. As regards the flexural strength, the SF-CF=75-25\% (M3) specimen reinforced with hybrid was the highest, but that of all FRM specimens except for the plain mortar (M11, M12) and SF-CF $=0-100 \%$ (M9, M10) specimens increased significantly. Particularly, the $\mathrm{SF}-\mathrm{CF}=50-50 \%$ (M6) specimen reinforced with hybrid turned out to have the highest equivalent flexural strength, a fact indicating presumably that the micro CF bears the same stress as the macro SF when the initial crack occurs and, after cracking occurs, the macro SF bears stress, which relieves the stress concentration borne by SF, resulting in higher equivalent flexural strength. In addition, it can be seen that macro SF has higher resistance to cracking and strain capacity than micro CF when the specimen is fractured. It was also made clear that, compared to the plain mortar, the single FRM and SF-CF hybrid FRM showed a tendency of significant increase for all including the maximum flexural strength and equivalent flexural strength, and that the equivalent flexural strength of the $\mathrm{SF}-\mathrm{CF}=50-50 \%$ (M6) specimen reinforced with hybrid increased by 4.2 to 10.5 times. On the other hand, the equivalent flexural strength ratio was evaluated as 0.69 to 0.73 and 0.42 to 0.71 for the single FRM specimen using only macro SF and the SF-CF hybrid FRM specimen, respectively, whereas the single FRM specimen using only micro CF was evaluated as 0.32 to 0.33 . And, the plain mortar specimen was evaluated as 0.17 to 0.39 . The $\mathrm{SF}-\mathrm{CF}=50-50 \%$ (M6) specimen reinforced with hybrid, particularly, had a slightly lower flexural strength than the SF-CF $=75-25 \%$ (M3) specimen, but the load-supporting capacity was the highest after cracking. As a result, the equivalent flexural strength ratio tended to be very high 
with 0.71 . Besides, in case of the SF-CF $=0-100 \%$ (M9, M10) specimen reinforced with hybrid, the maximum flexural strength, equivalent flexural strength, and equivalent flexural strength ratio were all low. Accordingly, the equivalent flexural strength and equivalent flexural strength ratio can be used as an important index to evaluate the load-supporting capacity after the maximum flexural strength. The equivalent flexural strength and equivalent flexural strength ratio showed a proportional relationship. On the other hand, the reason why the equivalent flexural strength has a smaller value than the flexural strength is, as in the test method proposed in ASTM C 1609/C 1609 M [19] and KS F 2566 [20], because the area under the load-deflection curve is calculated upto the section where the deflection is $2 \mathrm{~mm}$. Therefore, it is judged that applying the equivalent flexural strength is a rather conservative evaluation as it has a predetermined residual load and a large amount of flexural toughness even in the state of deflection of $2 \mathrm{~mm}$ or more.

Table 3. Test results of the maximum flexural strength and equivalent flexural strength.

\begin{tabular}{|c|c|c|c|c|c|c|}
\hline \multirow{2}{*}{$\begin{array}{l}\text { Specimens } \\
\text { designation }\end{array}$} & \multicolumn{2}{|c|}{ Fiber mix proportion by volume (\%) } & \multirow{2}{*}{$\begin{array}{l}\text { Fiber volume } \\
\text { fraction (\%) }\end{array}$} & \multirow{2}{*}{$\mathbf{f}_{\mathrm{r}}(\mathrm{MPa})$} & \multirow{2}{*}{$\mathrm{f}_{\mathrm{r}}{ }_{\mathrm{r}}(\mathrm{MPa})$} & \multirow{2}{*}{$\mathbf{f}^{{ }^{\prime}} / \mathbf{f}_{\mathrm{r}}$} \\
\hline & Macro SF & Micro CF & & & & \\
\hline M1 & \multirow{2}{*}{100} & \multirow{2}{*}{0} & \multirow{2}{*}{1.0} & 5.73 & 3.97 & 0.69 \\
\hline M2 & & & & 5.97 & 4.41 & 0.73 \\
\hline M3 & \multirow{2}{*}{75} & \multirow{2}{*}{25} & \multirow{2}{*}{1.0} & 8.16 & 4.76 & 0.58 \\
\hline M4 & & & & 7.11 & 4.40 & 0.62 \\
\hline M5 & \multirow{2}{*}{50} & \multirow{2}{*}{50} & \multirow{2}{*}{1.0} & 6.99 & 4.41 & 0.63 \\
\hline M6 & & & & 7.47 & 5.35 & 0.71 \\
\hline M7 & \multirow{2}{*}{25} & \multirow{2}{*}{75} & \multirow{2}{*}{1.0} & 6.42 & 3.06 & 0.47 \\
\hline M8 & & & & 5.22 & 2.20 & 0.42 \\
\hline M9 & \multirow[b]{2}{*}{0} & \multirow{2}{*}{100} & \multirow{2}{*}{1.0} & 4.74 & (1.59) & $(0.33)$ \\
\hline M10 & & & & 4.86 & $(1.56)$ & $(0.32)$ \\
\hline M11 & \multirow{2}{*}{ - } & \multirow{2}{*}{ - } & \multirow{2}{*}{ - } & 2.97 & $(0.51)$ & $(0.17)$ \\
\hline M12 & & & & 3.24 & (1.28) & $(0.39)$ \\
\hline
\end{tabular}

Notice) $f_{\mathrm{r}}$ : Maximum flexural strength, $f^{{ }^{\prime}}{ }_{r}$ : Equivalent flexural strength, $f_{r}{ }_{r} / f_{r}$ : Equivalent flexural strength ratio, () Is a value that did not reach $1 / 150(2 \mathrm{~mm})$ of the span.

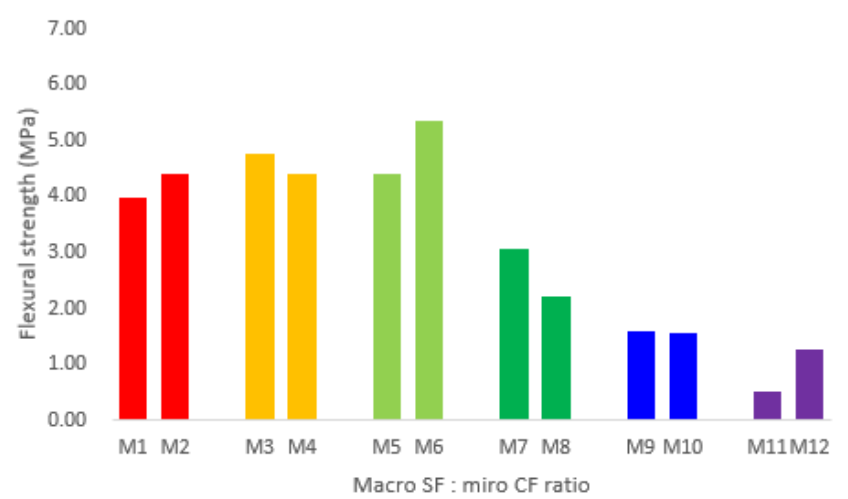

Figure 10. Variation in equivalent flexural strength calculation results of each specimen.

\subsubsection{Load-Deflection Relationship}

Figure 11 shows a load-deflection relationship curve of each specimen obtained in a four-point flexural load test. FRCC is known to exhibit a strain softening or strain hardening phenomenon by suppressing the crack initiation and propagation of cracks after cracking due to adhesion between fibers and matrix [24]. The flexural failure behaviors of reinforcing fibers can be classified into the pre-cracking stage and post-cracking stage. Before cracking, all specimens show almost similar linear behaviors and, after cracking, the load-deflection curve changes to non-linear, and the behavior of each specimen changes as the stress decreases after reaching the maximum load. As shown in Figure 11, in case of the plain mortar specimen and the single FRM specimen using only micro $\mathrm{CF}$, the given deflection did not reach $2 \mathrm{~mm}$ due to the brittle behavior and was destroyed at about 0.3 to $1.8 \mathrm{~mm}$. In case of the single FRM specimen using only macro SF and the SF-CF hybrid FRM specimen, however, the given deflection was destroyed at $2 \mathrm{~mm}$ or more due to the ductile behavior. As the amount of macro SF increased, the deflection was found to have a large amount of flexural toughness even after $2 \mathrm{~mm}$. In addition, the plain mortar specimen showed a linear behavior from about $9.9 \sim 10.8 \mathrm{kN}$ before the initial cracking until reaching the maximum load, and then was rapidly destroyed with occurrence of flexural cracks after reaching the maximum load, and there was almost no deflection since then. On the other hand, the single FRM specimen using only micro CF showed linear behavior from about $15.8 \sim 16.2 \mathrm{kN}$ to the maximum load, but deflection occurred when it was about $0.3 \mathrm{~mm}$ under the maximum load, and deflection decreased sharply after reaching the maximum load. In case of the SF-CF hybrid FRM specimen, however, deflection occurred when the maximum load was about 0.3 to $1.2 \mathrm{~mm}$ before and after, and deflection decreased gradually after reaching the maximum load without a rapid decrease while increasing a lot fairly. In case of the plain mortar, the specimen fractured brittly with occurrence of initial cracking, but the single FRM and SF-CF hybrid FRM suppressed propagation of cracking, and the initial crack strength increased significantly. And, all specimens displayed ductile fracture behaviors after cracking. In connection with the flexural fracture behavior, the maximum flexural strength is greatly affected by the number of micro $\mathrm{CF}$, but the ductile behavior after occurrence of cracking is thought to be largely influenced by macro SF. Therefore, by mixture of two or more fibers with different material properties in an appropriate ratio, any sudden brittle fracture due to the linear behavior of material can be 
prevented, and at the same time, it is possible to gain the strength and ductility which cannot be obtained just by

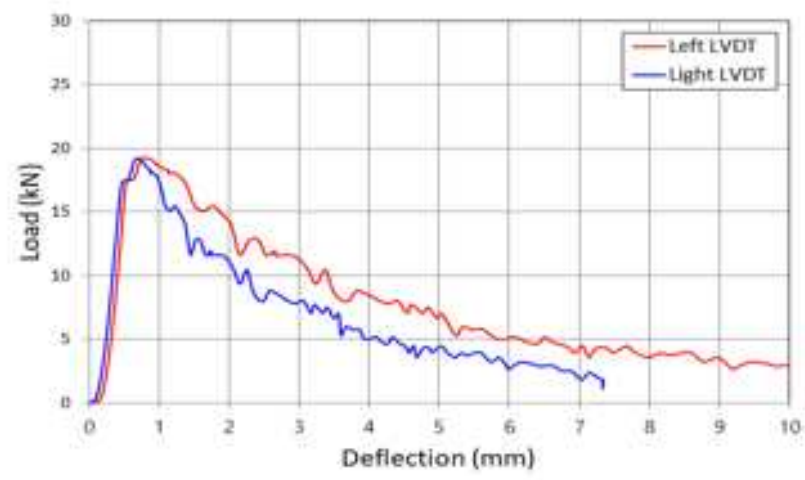

(a) M1

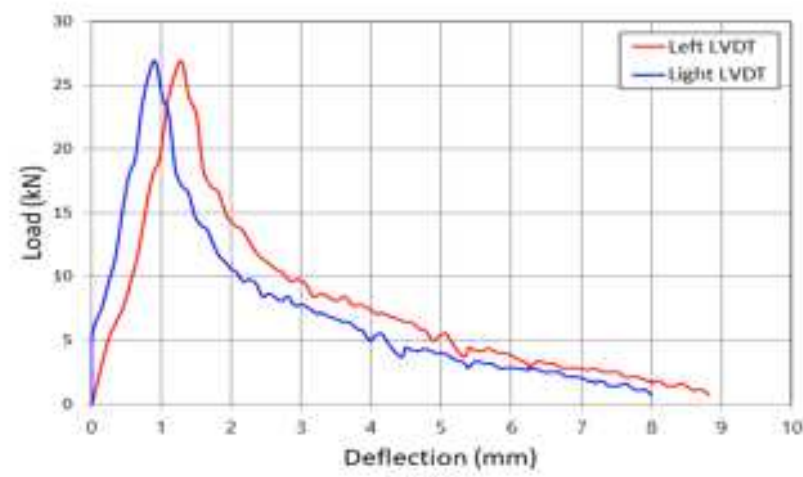

(c) M3

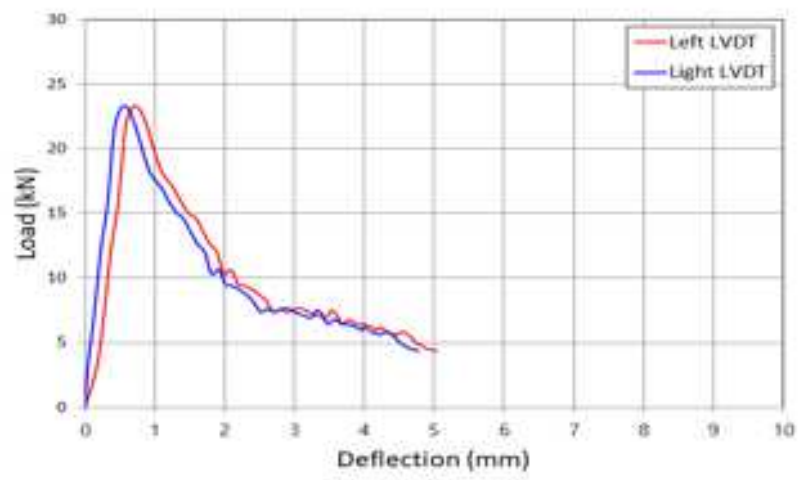

(e) $\mathrm{M5}$

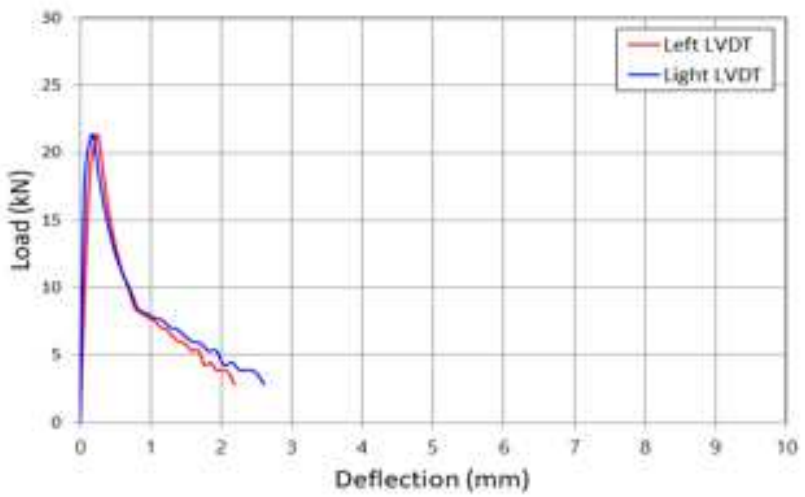

(g) $\mathrm{M7}$ reinforcing a single fiber, because different fibers share their roles.

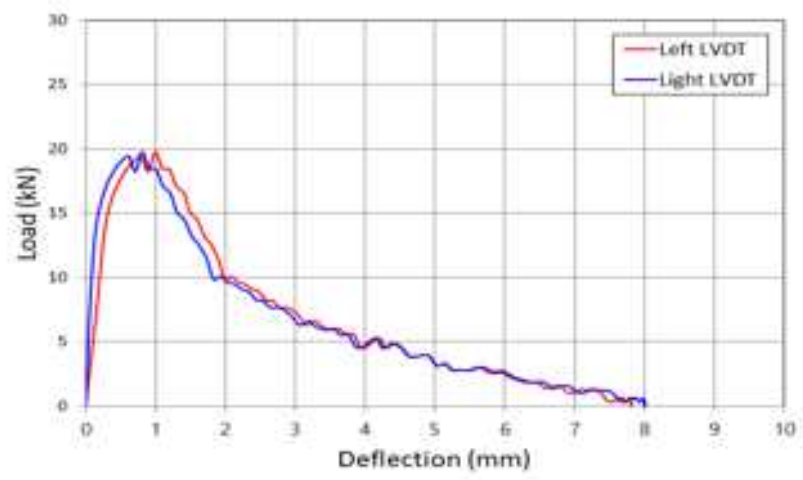

(b) $\mathrm{M} 2$

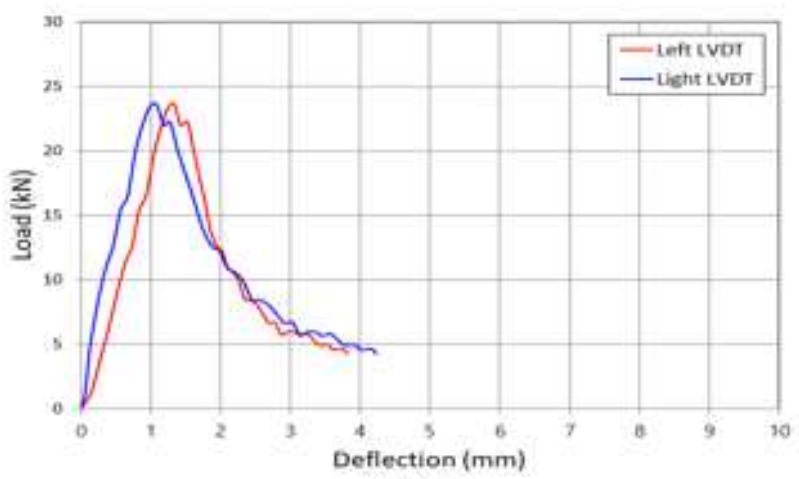

(d) M4

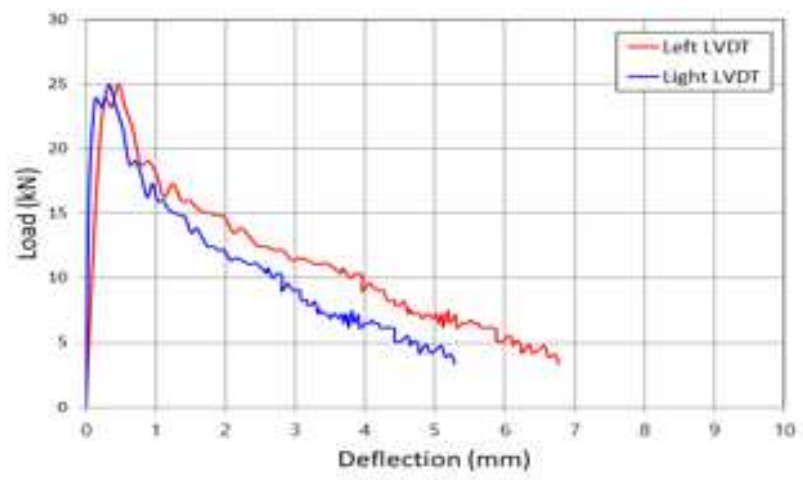

(f) M6

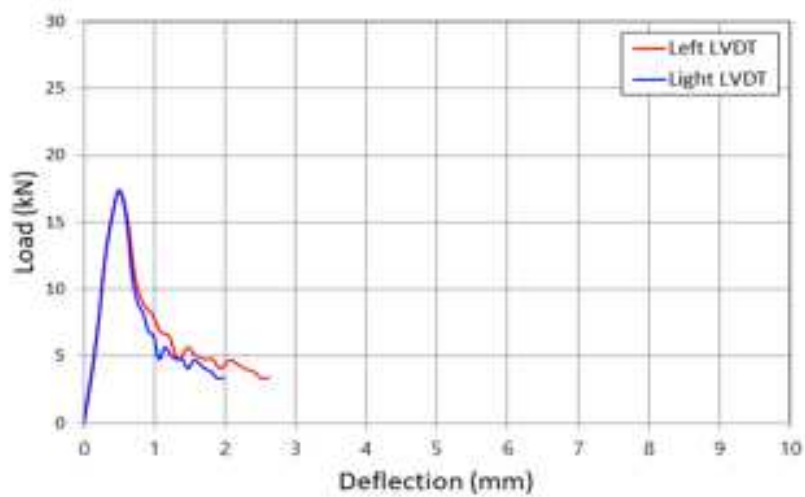

(h) M8 


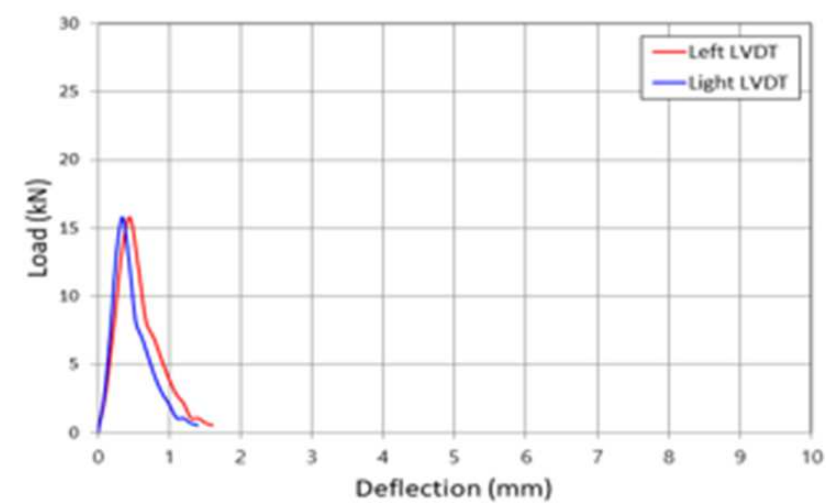

(i) $\mathrm{M} 9$

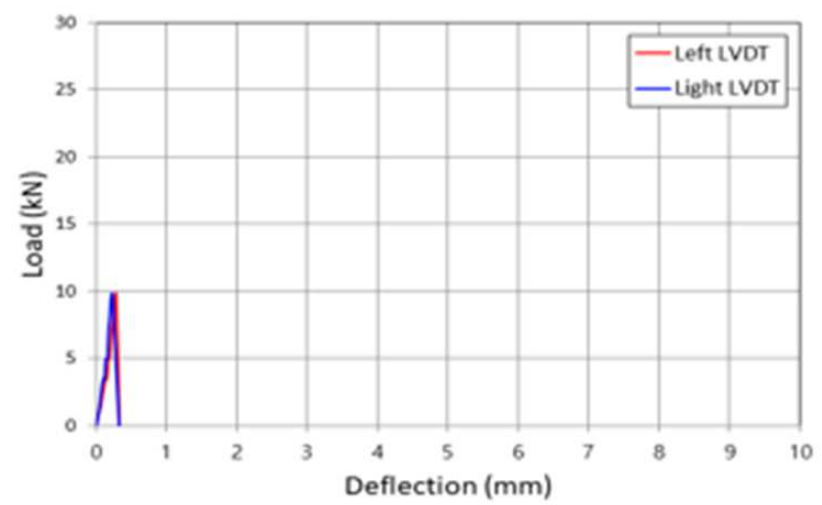

(k) M11

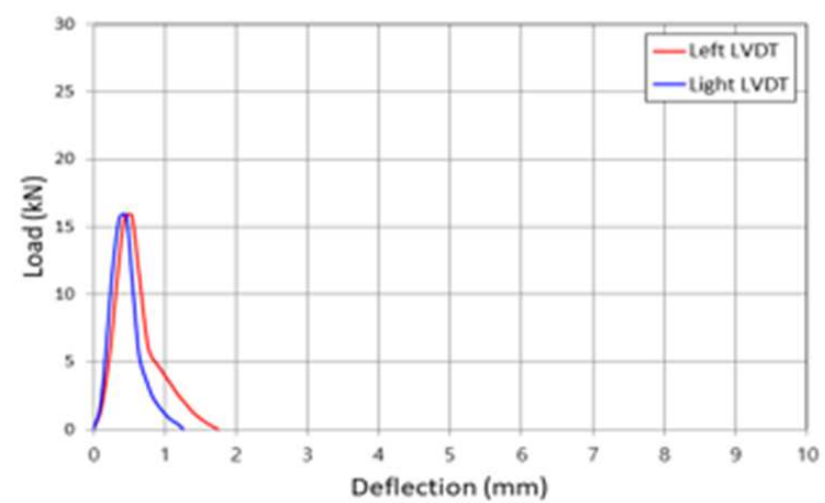

(j) $\mathrm{M} 10$

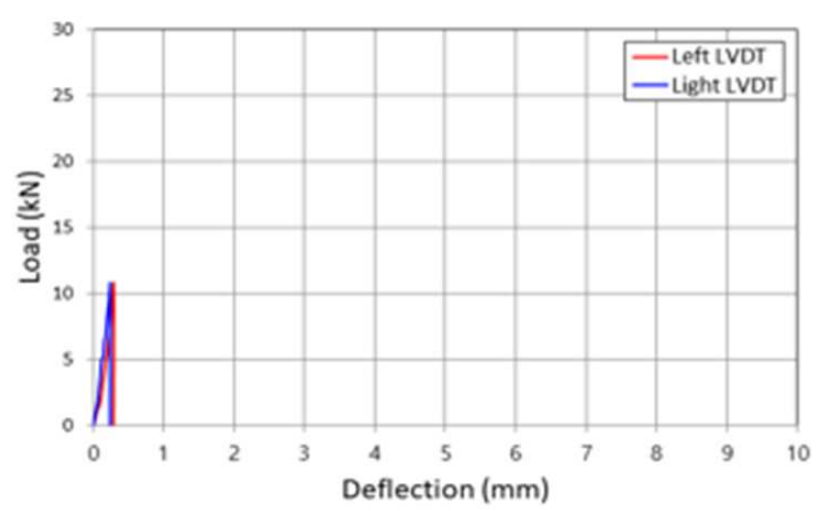

(1) M12

Figure 11. Load-deflection relation curves of all specimens.

Meanwhile, the deflection ratio of the maximum loads and corresponding deflections of each specimen compared with the plain mortar are shown in Table 4. Compared to the plain mortar specimen, the amount of deflection tended to increase in all specimens except for the SF-CF $=25-75 \%$ (M7) specimen reinforced with hybrid. It is evident from the review that, in case of the $\mathrm{SF}-\mathrm{CF}=100-0 \%$ (M1, M2) specimens reinforced with hybrid, the maximum load was at the level of $19.1 \mathrm{kN}, 19.9 \mathrm{kN}$, and the displacement was upto $0.69 \mathrm{~mm}, 0.73 \mathrm{~mm}$, and that, in case of the SF-CF=75-25\% (M3, M4) specimens, the maximum load was at the level of
$27.2 \mathrm{kN}$ and $23.7 \mathrm{kN}$, and the deflection was upto to the highest $1.12 \mathrm{~mm}$ and $1.27 \mathrm{~mm}$ due to the ductile behavior. Thus, the amount of increase in deflection from the relationship between the maximum loads and the corresponding deflections was in order of M4 $>$ M3 $>$ M2 $>$ M1> M5> M8, M9> M10>M11, M12> M7, with the $\mathrm{SF}-\mathrm{CF}=75-25 \%$ (M4) specimen reinforced with hybrid to be the largest. This is believed to have resulted from incorporation of fibers with high rigidity as well as from synergies between macro SF and micro $\mathrm{CF}$.

Table 4. Maximum loads and corresponding deflections obtained from the flexural test.

\begin{tabular}{|c|c|c|c|c|c|c|}
\hline \multirow{2}{*}{$\begin{array}{l}\text { Specimens } \\
\text { designation }\end{array}$} & \multicolumn{2}{|c|}{ Fiber mix proportion by volume (\%) } & \multirow{2}{*}{$\begin{array}{l}\text { Fiber volume } \\
\text { fraction (\%) }\end{array}$} & \multicolumn{2}{|c|}{ Maximum loads and corresponding deflections } & \multirow{2}{*}{$\begin{array}{l}\text { Ratio of } \\
\text { deflection }\end{array}$} \\
\hline & Macro SF & Micro CF & & Load (kN) & Deflection (mm) & \\
\hline M1 & & 0 & 10 & 19.1 & 0.69 & 2.65 \\
\hline M2 & 100 & 0 & 1.0 & 19.9 & 0.73 & 2.80 \\
\hline M3 & & & & 27.2 & 1.12 & 4.30 \\
\hline M4 & 75 & 25 & 1.0 & 23.7 & 1.27 & 4.88 \\
\hline M5 & & & & 23.3 & 0.65 & 2.50 \\
\hline M6 & 50 & 50 & 1.0 & 24.9 & 0.28 & 1.07 \\
\hline M7 & & & & 21.4 & 0.21 & 0.81 \\
\hline M8 & 25 & 15 & 1.0 & 17.4 & 0.54 & 2.07 \\
\hline M9 & & & & 15.8 & 0.54 & 2.07 \\
\hline M10 & 0 & 100 & 1.0 & 16.2 & 0.47 & 1.80 \\
\hline M11 & & & & 9.9 & 0.26 & 100 \\
\hline M12 & - & - & - & 10.8 & 0.26 & 1.00 \\
\hline
\end{tabular}

\section{Conclusions}

In the present study, the mechanical properties such as fluidity, compressive strength, and flexural performance of a single FRM and SF-CF hybrid FRM were compared and reviewed with plain mortar in five types by volume at a total fiber volume fraction of $1.0 \%$. The results could be summed up as follows.

1. The target table flow value of the plain mortar and the 
mortar using only macro SF was satisfied but, in the mixed SF-CF hybrid FRM, the table flow value fairly decreased as the micro CF increased. Especially, when only micro $\mathrm{CF}$ was used, the lowest table flow value was measured.

2. In case of the SF-CF=75-25\% (M3) specimen reinforced with hybrid, the compressive and flexural strengths were about $103 \%$ and $263 \%$, respectively, compared to the plain mortar. Although it was not very effective to improve the compressive strength, it showed high flexural strength.

3. In case of the SF-CF=50-50\% (M6) specimen reinforced with hybrid, the maximum flexural strength was a little lower, but the highest flexural toughness was obtained, and the synergistic reinforcement effect to improve the flexural performance by hybrid of macro SF with micro CF was confirmed.

4. The equivalent flexural strength and the equivalent flexural strength ratio can be used as an important index to evaluate the load-supporting capacity after the maximum flexural strength, and the relationship between the equivalent flexural strength and the equivalent flexural strength ratio tended to be proportional to each other. Therefore, it is judged that applying the equivalent flexural strength is a rather conservative evaluation as it has a predetermined residual load and a large amount of flexural toughness even in the state of deflection of $2 \mathrm{~mm}$ or more.

5. In case of the plain mortar specimen, the load-deflection relationship curve showed a clear tendency of brittle fracture behavior, whereas all FRM specimens had significantly improved toughness and strain capacity in the post-cracking stage, and showed stable ductile failure behavior after reaching the maximum load.

In order to increase the fluidity and compressive strength of the cement composite reinforced with hybrid, additional research and review are needed on the chemical treatment effect of the fiber.

\section{Acknowledgements}

This research was supported by Basic Science Research Program through the National Research Foundation of Korea (NRF) funded by the Ministry of Education (Grant no. NRF-2018R1A6A1A03025542). In addition, it was carried out with the support of research funding from Moowang Construction as a joint project with industry.

\section{References}

[1] Cao, M, Mao, Y, Khan, M, Si, W, Shen, S. (2018), "Different testing methods for assessing the synthetic fiber distribution in cement-based composites," Construction and Building Materials, 184, 128-142.

[2] Heo, G. H, Park, J. G, Kim, C. G. (2020), "Evaluating the resistance performance of the VAEPC and the PAFRC composites against a low-velocity impact in varying temperature," Advances in Civil Engineering, Volume 2020, https://doi.org/10.1155/2020/7901512.
[3] Yi, D. R, Ha, G. J. (2014), "Improvement of structural performance of RC beams retrofitted hybrid fiber using recycles coarse aggregate and ground granulated blast furnace slag," Journal of the Korea Institute for Structural Maintenance and Inspection, 18 (6), 1-10.

[4] ACI Committee 544. (1999), "Measurement of properties of fiber reinforced concrete," American Concrete Institute.

[5] Heo, G. H, Park, J. G, Song, K. C, Park, J. H, Jun, H. M. (2020), "Improving the interfacial bond properties of the carbon fiber coated with a Nano- $\mathrm{SiO}_{2}$ particle in a cement paste matrix," Advances in Civil Engineering, Volume 2020, https://doi.org/10.1155/2020/8838179.

[6] Naaman, A. E. (2002), "Toughness, ductility, surface energy and deflection-hardening FRC composites, proceedings of the JCI international workshop on ductile fiber-reinforced cementitious composites (DFRCC)," Application and Evaluation (DFRCC-2002), JCI, 33-57.

[7] Brandt. A. M. (2008), "Fibre reinforced cement-based (FRC) composites after over 40 years of development in building and civil engineering," Composites Structures, 86, 3-9.

[8] Zhang, P, Li, Q. F. (2013), "Effect of polypropylene fiber on durability of concrete composite containing fly ash and silica fume," Composites: Part B, 45, 1587-1594.

[9] Kim, H. J, Kim, N. W. (2020), "Enhancement of mechanical property of concrete structure using the macro and micro steel fibers," American Journal of Civil Engineering, 2020: 8 (1), 1-9.

[10] Banthia N, Sappakittipakorn M. (2007), “Toughness enhancement in steel fibre reinforced concrete through fiber hybridization," Cement and Concrete Research, 37, 1366-1372.

[11] Cao, M, Xie, C, Guan, J. (2019), "Fracture behavior of cement mortar reinforced by hybrid composite fiber consisting of $\mathrm{CaCO}_{3}$ whiskers and PVA-steel hybrid fibers," Composites Part A, 120, 172-187.

[12] Lawler, J. S. Wilhelm, T. Zampini, D, Shap, S. P. (2003), "Fracture processes of hybrid fiber-reinforced mortar," Materials and Structures, 36, 197-208.

[13] Pakravan, H. R, Latifi, M, Jamshidi, M. (2017), "Hybrid short fiber reinforced system in concrete: A review," Construction and Building materials, 142, 280-294.

[14] Kim, S, Yoo, D. Y. (2018), "Hybrid effects of steel fiber and carbon nanotube on self-sensing capability of ultra-high-performance concrete," Constr. Build. Mater, 185, $530-544$.

[15] Park, M. S, Shin, S. Y, Jeong, E. C, Kim, Y. S. (2016), “A study on mechanical property of high strength mortar reinforced with hybrid fibers," Journal of the Architectural Institute of Korea Structures \& Construction, 32 (7), 49-56.

[16] Yao, Y, Li. J, Wu. K. (2003), "Mechanical properties of hybrid fiber-reinforced concrete at low fiber volume fraction," Cement and Concrete Research, 33, 27-30.

[17] KS L 5105. (2007), "Test method for compressive of hydraulic cement mortar," Korea Agency for Technology and Standards, 1-5.

[18] KS L ISO 679. (2016), "Methods of testing cements-determination of strength," Korea Agency for Technology and Standards, 1-16.

[19] ASTM C 1609/C 1609 M. (2010), "Standard test method for flexural performance of fiber-reinforced concrete (using beam with third-point loading), “ASTM Standards, United States. 
[20] KS F 2566. (2014), "Standard test method for flexural performance of fiber reinforced concrete," Korea Agency for Technology and Standards, 1-10.

[21] Dehghani, A, Aslani, F. (2020), "The effects of shape memory alloy, steel, and carbon fibers on fresh, mechanical, and electrical properties of cementitious composites," Cement and Concrete Composites, http://doi:10.1016/J.cemconcomp.2020.103659.

[22] Heo, G. H, Park, J. G, Song, K. C, Park, J. H, Jun, H. M. (2020), "Mechanical properties of $\mathrm{SiO}_{2}$-coated carbon fiber-reinforced mortar composites with different fiber lengths and fiber volume fractions," Advances in Civil Engineering, Volume 2020, https://doi.org/10.1155/2020/8881273.

[23] Park, M. S, Shin, S. Y, Jeong, E. C, Kim, Y. S. (2016), “A study on the mechanical property of high strength mortar reinforced with hybrid fibers," Journal of the Architectural Institute of Korea Structure \& Construction, 32 (7), 49-56.

[24] Singh, S. P, Singh, A. P, Bajaj V. (2010), "Strength and flexural toughness of concrete reinforced with steel-polypropylene hybrid fibers," Asian Journal of Engineering (Building and housing), 11 (4), 495-507. 